\title{
Pros and cons of first aid training?
}

Published at www.cmaj.ca on July 12

$\mathrm{T}$ he Canadian Red Cross estimates that as many as half of Canadians have had some measure of first aid training in the last five years.

Is that adequate?

Excessive?

Should training be required for the whole population? Or only for some?

Is the curriculum valuable and current, or in need of an upgrade?

Experts appear divided on these issues.

Some, like the Heart and Stroke Foundation of Canada, argue that basic first aid, and especially cardiopulmonary resuscitation (CPR) training, should be an essential condition of citizenship, sort of an informal law of good Samaritanship.

The likelihood of surviving an out-ofhospital cardiac arrest improves when a bystander performs CPR, the foundation says. With 55 out of every 100000 Canadians and Americans suffering a heart attack every year, the potential health benefit for individuals is undeniable.

When combined with increased chances for fewer health complications and fewer trips to the hospital, the foundation argues that having more properly trained Canadians would ultimately yield even greater dividends to the nation's health care system.

That argument is so compelling to some nations, such as Great Britain, that they are proposing to significantly expand first aid training programs.

In other countries, such as Norway, or cities such as Seattle, Washington, bystander CPR rates are rising in tandem with the survival rate for out-ofhospital cardiac arrests, says Dr. Laurie Morrison, foundation spokeswoman and resuscitation researcher at St. Michael's Hospital in Toronto, Ontario.

But others are skeptical about the benefits of higher rates of training.

"Certainly it sounds good, but it hasn't been well studied," says Dr. Eli Segal, director of research for Urgences-santé, an emergency medical service agency,

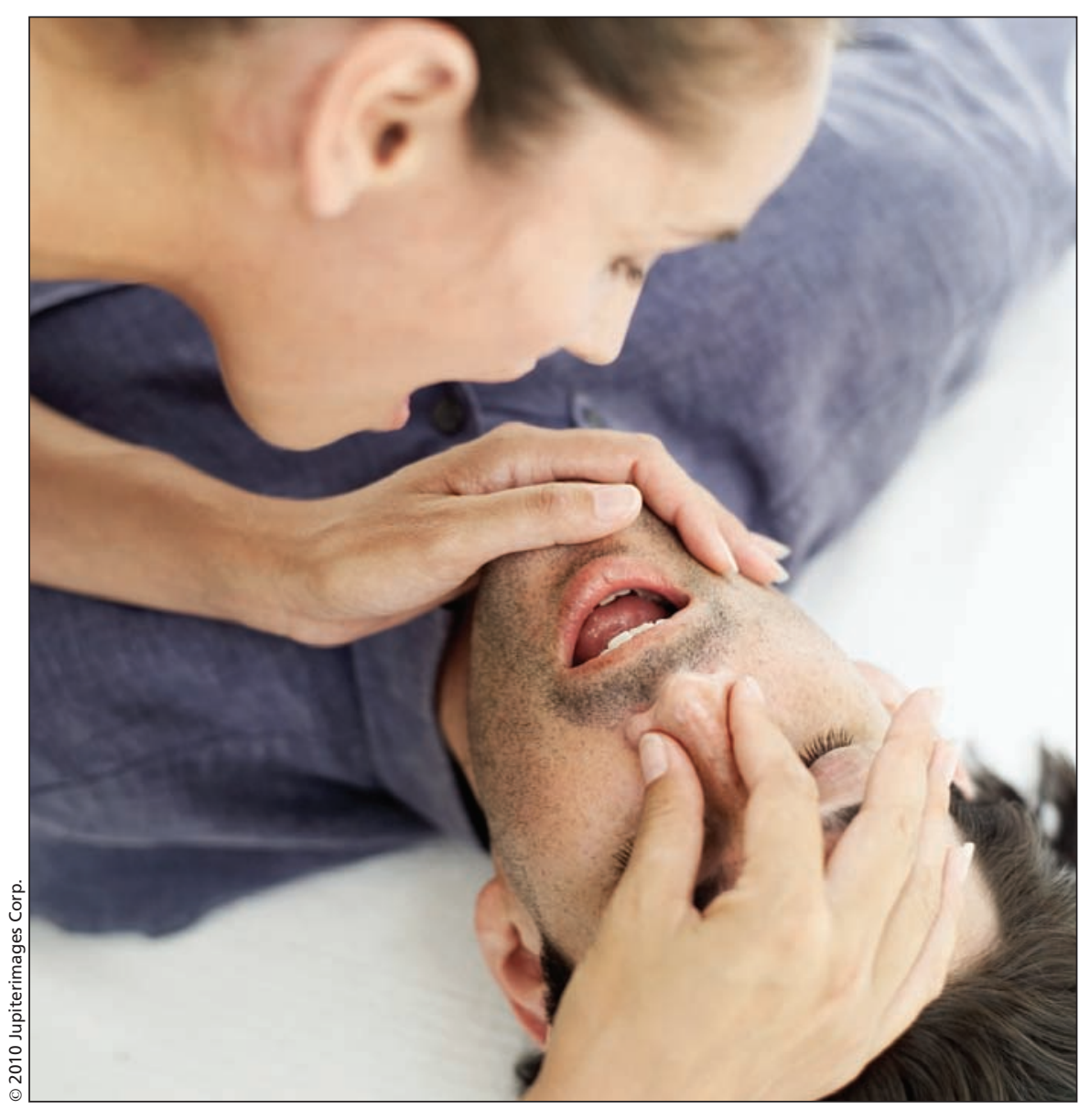

Some nations, like Great Britain, are proposing to significantly expand cardiopulmonary resuscitations and other forms of first aid training.

and assistant professor of family medicine at McGill University in Montréal, Quebec.

Segal says tertiary benefits from first aid training are practically impossible to quantify, primarily because when someone performs first aid successfully, the victim may never end up in an emergency room. "The consensus is that it's a good idea but we can't know if it's cost-effective."

First aid courses can be time consuming (three to four hours or even two days) and expensive (\$25-\$200). In terms of dollars and cents, says Segal, it may make more sense to train only a subsection of the population, starting with the people most likely to encounter emergency situations.
According to an American study comparing the cost of mass first aid training with the frequency of bystanders performing CPR, for each long-term survivor of a cardiac arrest, approximately 13695 other laypeople have to be trained (Am J Med $2005 ; 118: 58-67)$. That suggests it would be more efficient to target training programs at those who work or live with people more susceptible to heart attacks or strokes.

Yet, currently, the majority of people who take courses are under 30 , while most who witness cardiac arrests are older.

"The elderly are much more likely to have a heart attack and in general they're likely to be with another elderly 
person," says Dr. Alexander Dick, interventional cardiologist at the University of Ottawa Heart Institute in Ontario. "These are people who are historically not trained."

Few campaigns target the elderly for training, admits Les Johnson, national director of training for St. John Ambulance. They're often "hard to reach and hard to convince of the value of training."

Compounding that are extra complications, adds Dick. "You have to be careful that people who are ill shouldn't be made to feel responsible if they can't physically perform CPR."

Targeting certain groups for training also ignores the fact that emergencies can happen anywhere and at any time, Dick adds. "There are certainly populations that are more at risk, but there are a lot of people who die suddenly and you would have trouble predicting that."

But he adds that training more people of any age group in CPR would make it easier to find help during an emergency, when every minute is critical.

"Everyone should know basic life support because it's so important in survival," he says. "It's part of living that we should all know how to help each other. It's not complicated."

In fact, the skills are so simple that some researchers wonder if formal training is even necessary. A 2007 study found very little difference in the quality of skills learned by people taking a fourhour instructor-led CPR course and those teaching themselves with a 30minute DVD and a mannequin (Resuscitation 2007;74:476-86).

"Current CPR training is excellent but if that is limiting the number of people taking it, it should be made briefer and easier," Dick says.

Morrison concurs. Longer courses may be unnecessarily complicated, she says. Programs need to "take away the complexity of the skills."

"Use the quicker method of teaching," she adds, "because the bottom line is that we just want to know that people will get down on their knees and do chest compressions when they see someone in cardiac arrest."

Johnson, though, says there are added benefits to formal, classroom training. "I'm not putting down the concept of self-learning through a video because there is some evidence that that works.... (But in a group environment) you get to interact with other people and ask questions."

"In a class you also get obstructed airwaves, choking, emergency scene management - more than just the pump and blow," he adds.

Morrison says there's also a need to improve training in places, such as schools, where training is mandatory. "Some provinces have mandated that high school students learn CPR, but whether or not the schools are actually able to teach it [is questionable]. ... It's difficult for them to teach. There are a lot of things that compete with it in the curriculum."

"We have to make it easier for the schools to teach the kids," adds Morrison.

But whatever the form of training, Johnson says the most important thing is to simply get some training somewhere. "An emergency is most likely to happen at home to someone you know. If nothing else, there's an incentive." — Elyse Skura, Ottawa, Ont.

DOI:10.1503/cmaj.109-3293 